\title{
ANÁLISE DA ECOEFICIÊNCIA DO PROCESSO DE DESIGN DE MODA ZERO
}

\section{WASTE}

Eco-efficiency analysis of the zero-waste fashion design processo

\section{PEREZ, Iana Uliana I Especialista em Gestão Estratégica de Design}

Universidade Estadual de Londrina - UEL

ianauliana@hotmail.com

\section{CAVALCANTE, Ana Luisa B. Lustosa I Mestre em Engenharia de Produção}

Universidade Estadual de Londrina - UEL

anaboavista@gmail.com

\section{Resumo}

O presente estudo tem como objetivo apresentar o processo de design de moda zero waste e analisar sua ecoeficiência, diferenciando-o do processo convencional e do reaproveitamento de resíduos. A análise, realizada por meio da Sustainability Design Orienting Toolkit (SDO), considera as três dimensões da sustentabilidade, seus requisitos e diretrizes, de modo a balancear as vantagens e desvantagens quanto à sustentabilidade do design zero waste em comparação ao reaproveitamento.

Palavras-chave: Moda. Design zero waste. Análise de ecoeficiência. SDO toolkit.

\section{Abstract}

FThe present study aims to present the zerowaste fashion design process and analyze its ecoefficiency, differentiating it from the conventional process and reuse of waste. The analysis, conducted by Sustainability Design Orienting Toolkit (SDO), considers the three dimensions of sustainability, its requirements and guidelines in order to balance the advantages and disadvantages regarding the sustainability of the zero-waste design compared to the reuse.

Keywords: Fashion. Zero-waste design. Ecoefficiency analysis. SDO toolkit.. 


\section{INTRODUC̣̃̃O}

A ecoeficiência de produtos de moda é alvo de diversos trabalhos e pesquisas. Contudo, como afirmam Fletcher e Grose (2011, p. 12), "até o momento, a exploração de materiais tem sido o ponto de partida para a maior parte da inovação sustentável na moda." Segundo as autoras, essa estratégia funciona apenas como paliativo, pois, embora se enquadre na:

[...] esfera de ação da maioria dos designers e compradores", o uso de materiais sustentáveis encaixa-se "sem esforço em práticas de trabalho consagradas e no status quo do setor (mais do mesmo, só que 'mais verde'), sem demandar abalos reformadores dos negócios (FLETCHER; GROSE, 2011, p. 13).

Percebe-se, portanto, a necessidade de novas abordagens para a moda sustentável e o desenvolvimento de produtos de vestuário ecoeficientes que demandem reformulação do processo produtivo.

Nesse sentido, uma abordagem que tem sido apontada nos últimos anos é a do design zero waste. O desperdício de tecido é um dos principais problemas ambientais causados diretamente pela indústria de confecção de produtos de vestuário e moda. Embora seja alvo de diversos estudos na área de desenvolvimento de produtos, a maioria dos trabalhos se concentra no reaproveitamento de resíduos têxteis ou em estratégias para a redução do desperdício por meio da otimização do processo produtivo "pós-modelagem"1. Poucos estudos, sobretudo no Brasil, abordam a redução do desperdício durante o processo de design ${ }^{2}$, como proposto pela abordagem zero waste, que alia os processos de design e modelagem para "reduzir ou mesmo eliminar o desperdício de tecido decorrente do encaixe e corte." (PEREZ; MARTINS, 2012, p. 3).

Nos últimos anos, o processo de design de moda zero waste tem sido estudado e aplicado por designers ao redor do mundo. Publicações científicas e em sites ou jornais sobre o assunto, no entanto, ainda são recentes: as primeiras publicações datam de 2010. E poucos são os artigos escritos em português, já que o Brasil, como afirmam Ribeiro e Barcelos (2012), "ainda não possui designers de referência nesse segmento". Por isso, o processo zero waste ainda é

1 Refere-se a toda estratégia que não implique em modificação na modelagem.

2 "Embora a temática dos resíduos no setor de confecção de moda e vestuário tenha sido abordada em diversos trabalhos, o foco usualmente é dado em estratégias de reutilização. Poucos tratam da prevenção e, quando o fazem, dificilmente abordam a necessidade de modificação no processo de design para, de fato, prevenir a geração de resíduos." (PEREZ; MARTINS, 2013, p. 5758). 
pouco conhecido no país e, muitas vezes, é confundido com a mera reutilização de resíduos ou com o trabalho de apenas um designer, embora existam diversas técnicas e possibilidades de trabalho com esse processo, como apontado por Perez (2013).

Há, portanto, a necessidade de estudos que esclareçam as implicações do processo de design zero waste no desenvolvimento de produtos e em sua ecoeficiência, diferenciando-o do processo convencional e do simples reaproveitamento de resíduos. Para elucidar essa questão, o presente artigo visa realizar estudo teórico e analítico sobre produtos de moda e vestuário provenientes do processo de design de moda zero waste. O estudo parte da explicação deste processo e do esclarecimento das diferenças em relação ao processo convencional de design de moda e ao reaproveitamento de resíduos para, então, analisar, por meio da Sustainability Design Orienting Toolkit (SDO), a ecoeficiência do processo de design zero waste com foco na prevenção do desperdício em relação ao reaproveitamento de resíduos têxteis provenientes do processo convencional de design.

\section{FUNDAMENTAC̄̃̃ TEÓRICA}

Se antigamente as roupas eram projetadas para aproveitar toda a extensão do tecido, como ocorria com o saree indiano, o chiton romano e o kimono japonês, com a Revolução Industrial o tecido se tornou barato e "descartável". Já não era mais um problema desperdiçá-lo. Somando-se ao efeito da revolução, as mudanças da moda trouxeram novas demandas estéticas, que levaram a designs de vestuário cujos moldes não podem ser facilmente encaixados, gerando desperdício (RISSANEN; MCQUILLAN, 2011). Tendo em vista mudar esse cenário, diversos designers nos últimos anos tem resgatado o conceito "zero waste" presente em sarees e kimonos, dando origem ao design de moda zero waste.

Como indica Rosenbloom (2010), a taxa média de desperdício de tecido na indústria de confecção de moda varia entre 15\% e 20\%, gerando resíduos têxteis provenientes não somente do processo de corte como, sobretudo, "proporcionados pelo mau planejamento do processo produtivo" (RIBEIRO; BARCELOS; DAMASCENO, 2012, p. 8). Para Seiffert (2011), o desperdício de matéria-prima e insumos é um indicativo de falhas no projeto de produto. Portanto, para reduzir a geração de resíduos é essencial modificar o próprio processo de design.

Manzini e Vezzoli (2002, p. 12) corroboram essa visão ao afirmar que o desenvolvimento de produtos limpos requer, além de tecnologias limpas, "uma 
nova capacidade de design". A preocupação ambiental, segundo os autores, evoluiu desde o tratamento dos resíduos (políticas end-of-pipe), à modificação nos processos produtivos (tecnologias limpas) e ao redesign dos produtos (produtos limpos). Nesta perspectiva, pode-se afirmar que o reaproveitamento de resíduos têxteis caracteriza-se como uma política end-of-pipe, já que não propõe redução de resíduos na fonte ou modificações nos processos que geram tais resíduos. O design de moda zero waste, por sua vez, enquadra-se na perspectiva das tecnologias limpas, pois modifica o processo de design, atuando, assim, diretamente sobre a fonte de geração de resíduos. Mas o zero waste pode também ser considerado uma estratégia para o desenvolvimento de produtos limpos, uma vez que considera o redesenho do vestuário e de sua modelagem.

O design zero waste, para prevenir o desperdício, "contesta os parâmetros preestabelecidos de corte e modelagem industrial e [...] questiona a natureza do design e da produção de vestuário"3, transformando, assim, a maneira como o processo de design de moda é conduzido (GROSE, 2011, p. 6). O zero waste, portanto, representa a nova capacidade de design de que nos falam Manzini e Vezzoli (2002).

Fletcher e Grose (2011, p. 48) ressaltam que:

\begin{abstract}
Nos últimos anos, em relação às sobras da etapa de corte, surgiram conceitos de design com foco na sustentabilidade que vão desde usar os restos de pano em peças feitas de retalhos até reciclá-los como novos fios. [...] Mas os conceitos emergentes de design podem ir ainda mais longe e desenvolver formas totalmente novas de conceber a confecção de roupas. Essas técnicas [de design de moda zero waste] mostram que no talento e na habilidade prática dos designers, no contexto da sustentabilidade, é que estão a promessa real e os promotores de mudanças.
\end{abstract}

Como apontado por Jack (2012, p. 1), o design de moda zero waste utiliza "avanços técnicos e conceituais na modelagem, produzindo peças de vestuário que utilizam todo o tecido, ourela a ourela". Alison Gwilt ${ }^{5}$ vai além e afirma que, mais do que avanços na modelagem, o design zero waste aponta para a

3 "Zero Waste challenges the preordained parameters of industrialized pattern cutting and [...] It questions the nature of design and of making clothes [...] and yields the potential to transform not only the way we design, but also the way we think."

$4 \quad$ "Zero Waste designers are using technical and conceptual advances in pattern making, producing garments that use all of the fabric, selvedge to selvedge."

$5 \quad$ Entrevista concedida a Pitt (2012, p. 1): "A lecturer in fashion design at the University of Technology Sydney(UTS), Alison Gwilt, says we need to alter our approach to the production and design of clothes - 'to think about waste before we design clothing [...]'." 
necessidade de mudar a abordagem da produção e, sobretudo, do design de moda, pois se deve pensar no desperdício antes mesmo de iniciar o design dos produtos.

Desse modo, o design zero waste se diferencia do reaproveitamento de resíduos por evitar o desperdício antes que a peça de vestuário seja cortada. Embora alguns autores considerem o reaproveitamento de resíduos como uma técnica de design zero waste, este se destaca por modificar o processo de design de moda e por planejar, ainda durante a criação e modelagem, como possíveis resíduos serão aplicados à própria peça de vestuário que está sendo projetada ou a novos produtos. Assim, as sobras da modelagem não chegam sequer a se tornar resíduos.

Não há uma maneira única de se trabalhar com design de moda zero waste. Existem, na verdade, diversas técnicas e métodos. Em alguns casos, os moldes não precisam ser cortados. Em outros, a modelagem é projetada de modo a fazer com que todos os moldes se encaixem como em um quebra cabeças, modificando a modelagem quando necessário ${ }^{6}$. Destaca-se, aqui, o método jigsaw puzzle. Adotado pelos designers Holly McQuillan e Timo Rissanen, utiliza "modelagem plana mais parecida com a convencional em que cada parte do molde se encaixa como em um quebra-cabeça, e o que seria considerado excesso de tecido é aplicado à peça como acréscimo estético ou acabamento" (PEREZ, 2013, p. 6). Portanto, o que ocorre neste método é o aproveitamento de partes que usualmente seriam descartadas (como sobras do decote e cava), evitando, assim, que se tornem resíduos.

Independente da técnica utilizada, o design de moda zero waste caracterizase sempre por modificar radicalmente o processo de design, como apontado anteriormente. Usualmente, designers de moda criam suas peças por meio de esboços e desenhos. Já no processo zero waste, "a criação [...] é realizada por meio da modelagem, e não por desenhos ilustrativos que se tornam reinterpretados por modelistas qualificados." (ROBERTS, 2011 apud PEREZ, 2013, p. 8). Assim, "em vez de impor ao tecido um desenho e um modelo preconcebidos, o designer torna-se um facilitador, possibilitando que a forma surja e guiando sua evolução" enquanto "remodela" o formato dos moldes e a forma do vestuário até que todas as partes "se encaixem umas às outras" (FLETCHER; GROSE, 2011, p. 48).

\section{DESENVOLVIMENTO}

6 Importante ressaltar que, em alguns casos, esse método modifica substancialmente o formato dos moldes, gerando modelagens complexas que podem dificultar a compreensão do processo de montagem e costura da peça. 
Para a análise da ecoeficiência do processo de design zero waste em relação ao reaproveitamento de resíduos têxteis provenientes do processo convencional de design, foi utilizado o sistema Sustainability Design Orienting Toolkit (SDO), uma ferramenta qualitativa "criada para orientar o processo de design para soluções sustentáveis" (ANICET; BESSA; BROEGA, 2012, p. 142). Neste sistema, as três dimensões da sustentabilidade (ambiental, social e econômica) são consideradas, e para cada dimensão há seis requisitos com suas respectivas diretrizes (ou check-lists).

Segundo Vezzoli (2010, p. 234), um de seus desenvolvedores:

Ela é capaz de auxiliar os designers a definirem prioridades de sustentabilidade, analisando as melhores práticas, pelo uso de diretrizes de orientação de projetos para a sustentabilidade, verificando e visualizando as potenciais melhorias em relação a um sistema de referência existente.

A primeira etapa para utilizar a ferramenta ${ }^{7}$ é identificar as prioridades em relação às dimensões da sustentabilidade. Nessa fase, ainda é considerado apenas o sistema existente (no caso deste trabalho, o desenvolvimento de produtos de moda e vestuário por meio do processo de design convencional sem reutilização dos resíduos), e a definição de prioridades é feita por meio do preenchimento de check-lists referentes a cada um dos requisitos e indicação do nível de prioridade, que pode ser: alto $(A)$, médio $(M)$, baixo $(B)$ ou nulo $(N)$.

Estabelecidas as prioridades, parte-se para a análise de "casos de excelência com características de sustentabilidade", quando podem ser eleitos até dois estudos de caso para comparar suas soluções ao sistema existente (VEZZOLI, 2010, p. 241). Para a presente análise, elegeu-se como estudo de caso 1 o reaproveitamento de resíduos gerados pelo processo convencional de design de moda e, para o estudo de caso 2 , o uso do processo de design de moda zero waste com foco na prevenção do desperdício.

Para realizar a análise, deve-se responder aos check-lists e indicar, para cada estudo de caso, o nível de melhoria proporcionada em relação ao sistema existente: melhoria radical $(++)$, melhoria incremental $(+)$, sem mudanças significantes ( $(=)$ ou depreciação (-). Como resultado, o sistema gera um diagrama de radar para cada dimensão da sustentabilidade, no qual é possível visualizar em que requisitos há melhorias e comparar os resultados dos dois estudos de casos entre si e em relação ao sistema existente.

7 A descrição do uso da ferramenta SDO é baseada no texto explicativo de Vezzoli (2010, p. 234-242). 
Foi utilizado, para o estudo apresentado neste artigo, o sistema SDO online ${ }^{8}$. Conforme relatado anteriormente, a análise adotou como sistema de referência o desenvolvimento de produtos de moda e vestuário por meio do processo de design convencional, no qual não há preocupação com o meio ambiente ou causas sociais.

Tendo em vista estruturar a análise, considerou-se como referência para o estudo do reaproveitamento de resíduos o Banco do Vestuário da cidade de Caxias do Sul, no Rio Grande do Sul (estudo de caso 1). Trata-se de um projeto da Federação das Indústrias do Estado do Rio Grande do Sul (FIERGS) cuja principal função "é receber, identificar e separar resíduos industriais têxteis da região e repassá-los às associações comunitárias, aos clubes e entidades que utilizam esses resíduos como matéria-prima para o desenvolvimento de novos produtos" (DE ROSS; DA SILVA; DE CARLI, 2012, p. 79). Embora os resíduos da indústria de confecção de vestuário sejam, em alguns casos, reaproveitados pela própria empresa que os gerou ou por outra indústria, o mais comum é serem destinados a projetos sociais. Por isso é considerado como referência para o presente estudo o Banco do Vestuário. Outra razão para esta escolha é o fato de haver extensa bibliografia sobre a atuação desse projeto, o que favorece sua análise.

Quanto ao processo de design de moda zero waste (estudo de caso 2), devido à diversidade de métodos e técnicas de design zero waste, para a análise comparativa foi utilizado como referência o método jigsaw puzzle, citado anteriormente neste artigo, pois é considerado o mais aplicável à realidade produtiva da indústria de confecção de moda e vestuário. Isso porque o jigsaw puzzle não exige investimento em maquinário, como máquinas de corte a laser, e tem como resultado modelagens mais próximas às convencionais, o que facilita a compreensão do processo de montagem e confecção da peça de vestuário. Ademais, enquanto alguns métodos de design zero waste, a despeito de reduzirem o desperdício, consumam maior quantidade de tecido ${ }^{9}$, o jigsaw puzzle permite maior controle sobre o consumo de matéria-prima.

Sendo o foco deste estudo a minimização do desperdício e da geração de resíduos, para a análise não foram consideradas outras melhorias ambientais aplicadas aos estudos de caso senão aquelas diretamente relacionadas às estratégias analisadas para a redução do desperdício.

\section{RESULTADOS}

8 Disponível online em <http://www.sdo-lens.polimi.it/>. Acesso em: 21 nov. 2013.

9 O método "subtraction cutting", por exemplo, desenvolvido pelo designer Julian

Roberts, chega a usar três metros de tecido para o desenvolvimento de um único vestido. 
A seguir, são apresentados os diagramas com os resultados das análises realizadas. Neles, o sistema existente é representado pela circunferência central, onde está indicado o nível de prioridade de cada requisito. $\mathrm{O}$ estudo de caso 1, relativo ao reaproveitamento, é demonstrado em cinza escuro, e, em cinza claro, o estudo de caso 2, sobre o processo de design zero waste. Nas caixas de texto à esquerda e à direita, chamadas de "post-its virtuais", podemse ler anotações e comentários relativos a cada requisito. Em alguns casos, são indicadas em post-its possibilidades de melhoria da ecoeficiência dos sistemas analisados.

Figura 01- Diagrama de radar da dimensão ambiental

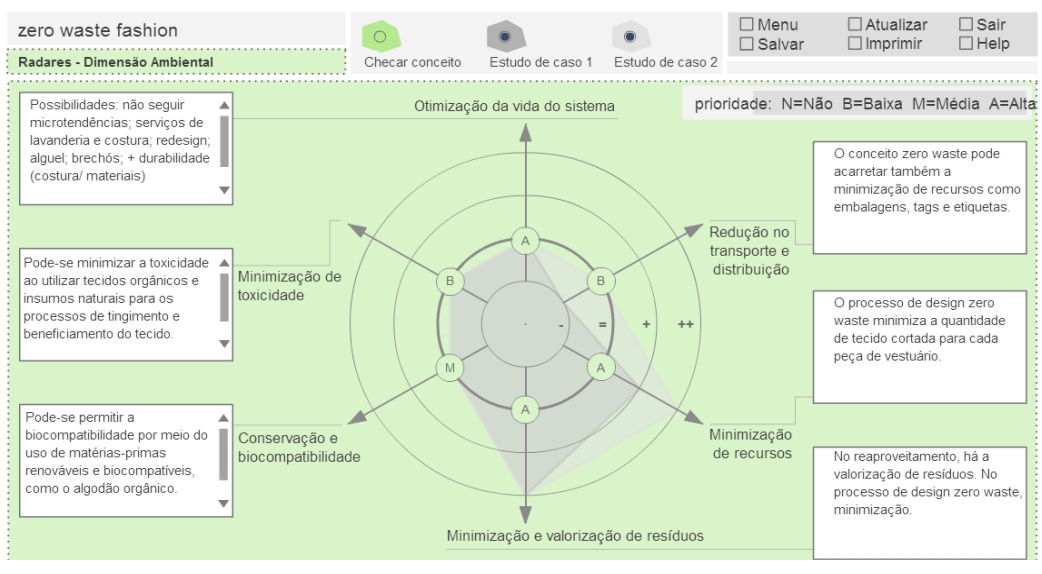

Fonte: Autor.

A primeira análise realizada foi quanto à dimensão ambiental. Como pode ser visualizado na figura 1, em ambos os casos há minimização e valorização dos resíduos: enquanto o processo de design zero waste, prioritariamente, reduz o desperdício, o reaproveitamento valoriza os resíduos, que se tornam insumo de uma nova produção.

O processo de design zero waste, no entanto, possibilita maior minimização de recursos se comparado ao reaproveitamento de resíduos. Isso porque o método "jigsaw puzzle" considera a redução do consumo de materiais no desenvolvimento do produto. Ademais, o conceito zero waste, para ser completo e comunicado pelo produto, traz a necessidade de eliminar também o excesso de materiais secundários ou de suporte, como etiquetas ou tags. Já no reaproveitamento, há dois processos: o desenvolvimento de um produto cujos resíduos serão reaproveitados para o segundo processo, o de desenvolvimento de um novo produto que incorpore estes resíduos. No primeiro não há preocupação em reduzir recursos. No segundo, embora haja consumo de matéria-prima descartada pelo processo anterior, podem ser acrescentados novos materiais para o desenvolvimento do produto e há consumo de outros recursos, como energia para a produção do novo produto e combustível para 
o transporte até o Banco Vestuário e, de lá, para o local de reutilização. Por isso, no reaproveitamento há depreciação quanto ao requisito de redução no transporte e distribuição. No processo de design zero waste, embora o sistema de transporte e distribuição permaneça o mesmo em relação ao sistema de produção existente, há a possibilidade de melhorar esse requisito caso o conceito zero waste seja expandido para além do produto, podendo-se reduzir o uso de embalagens de forma a eliminar o que não for estritamente necessário.

Quanto à dimensão socioética, o reaproveitamento de resíduos permite melhoria radical no requisito "integrar pessoas marginalizadas", como pode ser observado na figura 2. O processo de design zero waste em si não propõe mudanças significantes nesse aspecto, mas a maioria dos trabalhos com reaproveitamento de resíduos, sim. O caso considerado aqui como referência é um exemplo: o Banco do Vestuário proporciona ocupação aos detentos do Presídio Municipal e gera trabalho e renda para artesãos e comunidades carentes que utilizam seus resíduos como insumo, além de promover oficinas para artesãos e cursos de artesanato e de capacitação em corte e costura para pessoas dessas comunidades (DE ROSS; DA SILVA; DE CARLI, 2012).

Figura 02- Diagrama de radar da dimensão socioética

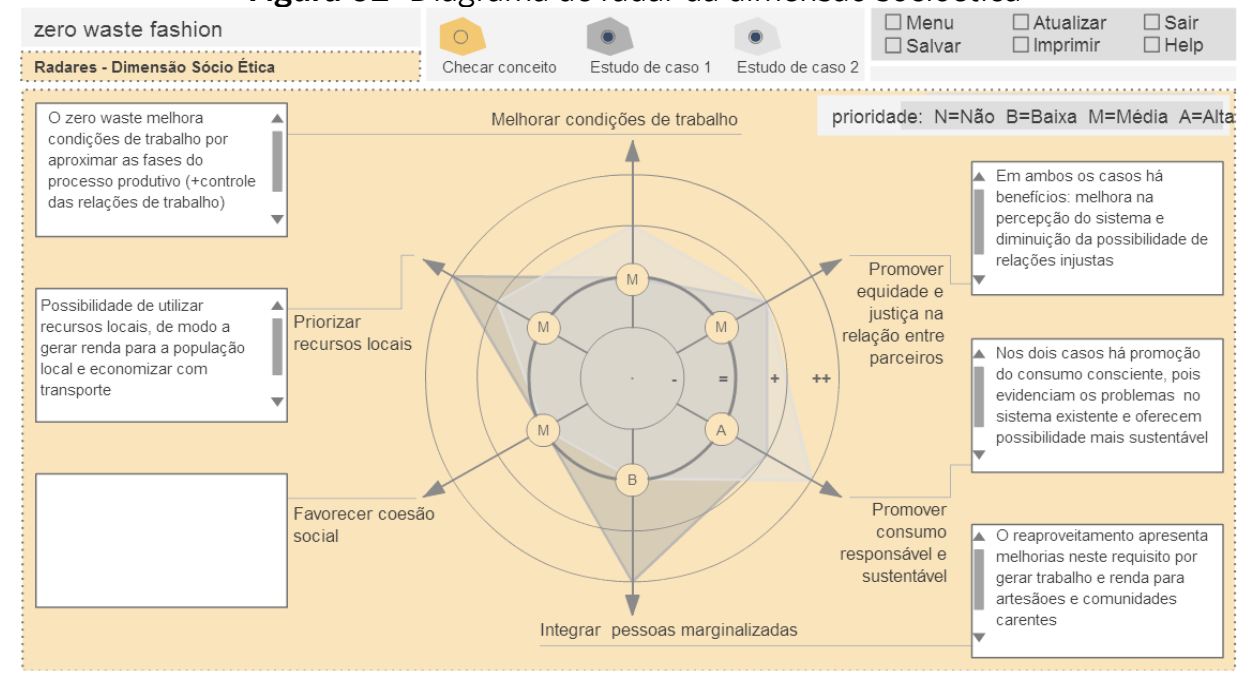

Fonte: Autor.

No requisito "melhorar condições de trabalho", consideram-se questões como remuneração justa, carga horária, saúde e segurança no trabalho. Quanto ao trabalho do Banco do Vestuário, não são esclarecidas essas condições durante o processo de reaproveitamento dos resíduos doados às entidades que os utilizam como insumo. E devem-se considerar ainda as condições de trabalho nas empresas doadoras de resíduos têxteis, já que também fazem parte do sistema de reaproveitamento. Portanto, não são notadas melhorias significativas quanto a esse requisito em relação ao sistema atual de desenvolvimento de produtos 
de moda. Por sua vez, no caso do processo de design zero waste considera-se haver melhoria incremental, pois ele aproxima o design do processo produtivo.

No processo convencional, como apontado por Roberts (2013), o designer é quem menos toca na peça de vestuário, pois muitas vezes o design é realizado longe da produção. O exemplo clássico dessa distância é o de peças projetadas em países europeus e confeccionadas na Ásia ou África, onde os custos produtivos são consideravelmente menores, mas boas condições de trabalho não são asseguradas. Mesmo quando design e produção são realizados em um único país, contudo, existe a possibilidade de haver distanciamento entre as etapas: elas podem ocorrer em cidades diferentes, principalmente quando a confecção das peças é terceirizada.

Quando há terceirização do processo produtivo, o designer e a empresa responsável pelos produtos tem menos controle sobre essa etapa. Se a empresa contratada encontra-se na mesma cidade ou região, ainda é possível estabelecer uma rotina de verificação, contudo o mais comum é a terceirização ocorrer em outra cidade, estado ou país onde os custos produtivos sejam menores. Esse distanciamento geográfico muitas vezes acarreta no distanciamento das responsabilidades da empresa contratante, devido à dificuldade de verificação do processo produtivo e das condições de trabalho. É difícil, portanto, garantir a transparência desta etapa produtiva.

O processo zero waste rompe esse distanciamento entre as etapas, uma vez que nele design, modelagem e prototipagem são realizados em um mesmo momento, pois todos fazem parte do seu processo criativo. Por isso, a ligação do design com a produção é mais forte, o que incentiva a aproximação de todo o processo produtivo, de modo que haja maior controle sobre a confecção das peças, propiciando o monitoramento das condições de trabalho.

Quanto à promoção do consumo responsável e sustentável, ambos os casos possibilitam melhorias por permitirem que o consumidor tenha mais conhecimento sobre as relações que ocorrem ao longo da cadeia produtiva quanto à sustentabilidade. Uma empresa que trabalhe com o processo de design zero waste, ao divulgar seu trabalho, jogará luz sobre a questão do desperdício e sustentabilidade no processo produtivo da indústria de moda. Ademais, o design zero waste é muitas vezes relacionado ao open design, pois o plano de encaixe da modelagem é sempre divulgado para mostrar o aproveitamento de tecido. E marcas como a David Andersen Copenhagen ${ }^{10}$ compartilham com o público, em seus sites ou blogs, todo o processo de desenvolvimento e confecção das peças, tornando-o transparente, de modo a trabalhar com a sustentabilidade não somente no âmbito do produto, mas refletida também em ações e na 10 http://www.zero-wastebydavidandersen.com/ 
produção. Isso promove o consumo consciente na medida em que expõe ao consumidor todo o processo produtivo, de forma que ele saiba exatamente 0 que está comprando e como foi produzido. Portanto, nesse requisito, o design zero waste proporciona melhoria radical, enquanto o reaproveitamento de resíduos apresenta apenas a incremental.

Já no requisito "priorizar recursos locais", considera-se haver melhoria radical no caso do reaproveitamento, pois há valorização dos valores culturais e identidades locais devido à promoção do artesanato, já que o Banco do Vestuário oferece oficinas de artesanato e capacitação de artesãos, além de fornecer insumos para a produção. Há também, nesse caso, fortalecimento de comunidades locais e consequente impacto positivo para seu bem estar e qualidade de vida, pois o trabalho do Banco propicia a geração de trabalho e renda para essas comunidades. Já o processo de design zero waste apresenta melhoria incremental por promover a aproximação do design e da produção. Assim, ao invés de contratar o serviço de confecção de uma facção de outra cidade ou país, uma empresa que trabalhe com design zero waste provavelmente procurará uma facção mais próxima, gerando trabalho e renda para a comunidade local.

Finalizando a análise da dimensão socioética, entende-se que em ambos os casos há melhoria no requisito "promover equidade e justiça na relação entre parceiros", pois todas as melhorias anteriormente discutidas permitem que haja menos críticas por parte de parceiros e clientes sobre o sistema de moda, além de haver menor possibilidade de relações injustas entre parceiros e colaboradores.

Já na dimensão econômica, embora os dois casos apresentem melhorias por agregar valor para as empresas e para os clientes, como pode ser observado na figura 3, o design zero waste apresenta resultados melhores. Ele agrega mais valor para as empresas, pois permite economia de matéria-prima, o que torna os produtos mais rentáveis, e possibilita a produção em série, aumentando a rentabilidade da empresa, o que é mais difícil no reaproveitamento, quando a baixa disponibilidade de um tecido ou resíduo específico permite a confecção de um número limitado de peças do mesmo modelo. No reaproveitamento também não acontece a economia de matéria-prima no primeiro ciclo produtivo (o que gera os resíduos doados para o Banco do Vestuário), e os produtos resultantes do reaproveitamento não necessariamente serão mais rentáveis do que outros similares (artesanato, por exemplo), embora os insumos utilizados sejam provenientes de doação. 
Figura 03- Diagrama de radar da dimensão econômica

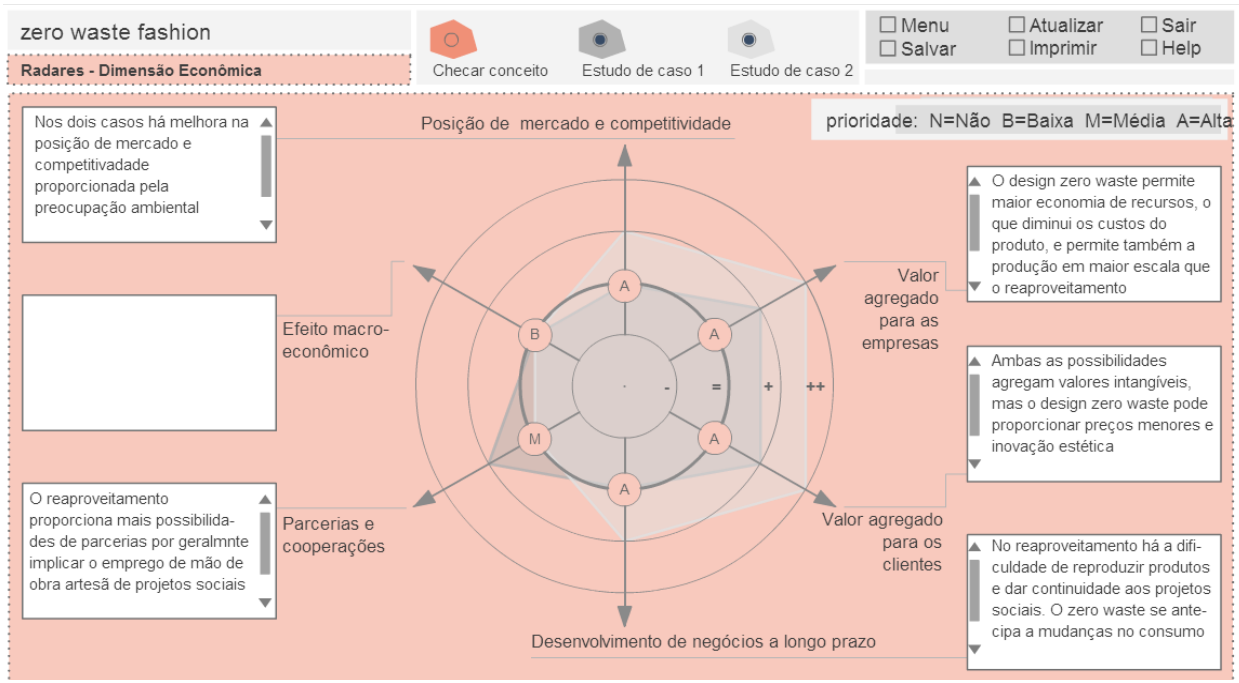

Fonte: Autor.

Com relação ao valor agregado para os clientes, produtos resultantes do reaproveitamento apresentam valor por serem, geralmente, únicos e artesanais, mas produtos zero waste podem apresentar mais valor agregado. Primeiro por que a redução do desperdício pode tornar o produto não só mais sustentável, como também mais barato e competitivo, mas também por que o processo zero waste permite inovação na forma e torna mais claro para o consumidor um valor concreto, que é a economia de material.

No requisito "desenvolvimento de negócios em longo prazo", o reaproveitamento não apresenta melhorias, pois, embora o Banco do Vestuário apresente estrutura para se manter e desenvolver, o trabalho com artesanato e comunidades carentes apresenta, muitas vezes, dificuldades quanto à retenção de seus beneficiados no projeto, o que pode comprometer o desenvolvimento em longo prazo do trabalho das entidades que utilizam os resíduos do Banco. Já o processo zero waste não apresenta essa dificuldade e ainda prevê mudanças de necessidades dos clientes, afinal a empresa atende à crescente demanda por produtos mais sustentáveis.

O reaproveitamento de resíduos, contudo, apresenta melhorias quanto a parcerias e cooperações, ao contrário do design zero waste, que não implica em mudanças significativas nesse sentido. $O$ trabalho realizado pelas entidades que reaproveitam resíduos ocorre, com frequência, na forma de cooperativas de artesãos. E o próprio Banco do Vestuário trabalha com inúmeras parcerias. Como afirmam De Ross, Da Silva e De Carli (2012, p. 80): 
de colaboração e cooperação entre empresas privadas, entidades, Poder Público e sociedade civil, que planejam, executam, avaliam e aprimoram os serviços e processos do banco.

Quanto à posição de mercado e competitividade, considera-se não haver melhorias significativas no caso do reaproveitamento, pois para a empresa doadora de resíduos não há grandes mudanças neste sentido, e para as entidades que recebem as doações a posição e competitividade depende da sua estrutura e atuação no mercado, fatores que não ficam muito claros para poder-se avaliar. Já no caso de uma empresa que trabalhe com design zero waste, sua posição de mercado se beneficia pela atuação como empresa consciente e responsável, comprometida com a redução do desperdício.

\section{CONSIDERAC̣ÕES FINAIS}

Por evitar o desperdício de tecido, o processo de design de moda zero waste apresenta inúmeras diferenças com relação ao processo convencional. Ele contesta seus parâmetros, exige mais comprometimento do designer e proporciona trabalho interdisciplinar, aproximando o design da modelagem, corte e prototipagem.

Embora tanto o zero waste quanto o reaproveitamento atuem para a redução do desperdício, tratam-se de diferentes formas de trabalho. $O$ reaproveitamento de resíduos não modifica o modelo atual de produção, enquanto o processo zero waste propõe mudanças radicais na forma como o design é concebido. Um atua para remediar um problema já existente os resíduos gerados pelas empresas de confecção de produtos de moda. O outro foca na prevenção desse problema. Essas diferenças entre as estratégias de prevenção e reaproveitamento se refletem na ecoeficiência dos modelos adotados, como demonstrado pelos diagramas de radar gerados pela SDO toolkit, que permitiram análise mais assertiva, tendo como referência os requisitos das três dimensões da sustentabilidade e suas respectivas diretrizes.

Pode-se constatar que o processo de design de moda zero waste apresenta melhores resultados em oito dos requisitos, enquanto o reaproveitamento mostra-se mais eficaz em apenas três. Conclui-se, então, ser o processo de design zero waste mais eficiente e eficaz do que o reaproveitamento com relação à sustentabilidade, sobretudo quanto às dimensões ambiental e econômica. Tanto que a própria Política Nacional de Resíduos Sólidos dispõe em suas diretrizes que, para a gestão de resíduos, a não geração e redução tem maior prioridade que a reutilização. 
A análise mostra, portanto, a importância de dar continuidade aos estudos do design de moda zero waste, já que este apresenta melhores resultados em relação ao reaproveitamento, embora a aplicação deste seja mais fácil e, por isso, mais difundida atualmente. É importante, entretanto, ressaltar que, a despeito de o reaproveitamento ser mais difundido no âmbito da moda que o design zero waste, ambos são ainda muito incipientes e necessitam de educação ambiental para seu desenvolvimento. Uma abordagem não é mais válida do que a outra, as duas podem e devem coexistir e se desenvolver mais. Deve-se apenas ter o cuidado para saber diferenciá-las, pois apresentam dinâmicas e implicações distintas com relação ao design e à sustentabilidade.

Ainda é preciso estudar e aprimorar aspectos do design zero waste, como sua forma de aplicação na indústria de larga escala. Contudo, embora sejam muitos os desafios apresentados pelo processo de design de moda zero waste, seus benefícios são inegáveis, o que incentiva seu desenvolvimento. Ademais, caso sejam adotadas outras estratégias sustentáveis em conjunto, como uso de matérias-primas de baixo impacto, o zero waste possibilita o desenvolvimento de produtos sustentáveis considerando todos os pontos de seu ciclo de vida, desde a pré-produção ao pós-consumo.

\section{REFERÊNCIAS}

ANICET, A.; BESSA, P.; BROEGA, C. A quantificação da

sustentabilidade no design têxtil. In: DE CARLI, A. M. S.; VENZON, B. L. S. Moda, sustentabilidade e emergências. Caxias do Sul: Educs, 2012. p. 135-147.

DE ROSS, G. E.; DA SILVA, F. P.; DE CARLI, A. M. S. Transformando resíduo em benefício social: Banco do Vestuário. In: DE CARLI, A. M. S.; VENZON, B. L. S. Moda, sustentabilidade e emergências. Caxias do Sul: Educs, 2012. p. 67-84.

FLETCHER, K.; GROSE, L. Moda \& sustentabiliade: design para mudança. São Paulo: Senac, 2011.

GROSE, L. Foreword. In: RISSANEN, T.; MCQUILLAN, H. YIELD: making fashion without making waste. 2011. Disponível em: <http://www. yieldexhibition.com/yieldexhibition-catalogue.pdf>. Acesso em: 23 mar. 2013. p. 6.

JACK, T. Zero Waste Fashion. 2012. Disponível em: <http://www. melbournereview.com.au/features/article/zero-waste-fashion-2012>. Acesso em: 30 abr. 2013 
MANZINI, E.; VEZZOLI, C. O desenvolvimento de produtos sustentáveis: os requisitos ambientais dos produtos industriais. São Paulo: Edusp, 2002

PEREZ, I. U. Nova abordagem para a prática do design de moda: processo zero waste. In: COLÓQUIO INTERNACIONAL DE MODA, 9, 2013, Fortaleza. Disponível em: <http://www.coloquiomoda.com.br/anais/9coloquio-de-moda-Comunicacao-Oral-EIXO-8-SUSTENTABILIDADE. php>. Acesso em: 30 out. 2013.

PEREZ, I. U.; MARTINS, S. B. Desenvolvimento de Produtos de moda masculina com redução de retraços têxteis. In: CONGRESSO BRASILEIRO DE PESQUISA E DESENVOLVIMENTO EM DESIGN, 10, 2012, São Luís. CD-ROM

PEREZ, I. U.; MARTINS, S. B. Prevenção do desperdício no setor de vestuário e moda: inovação no processo de design. ModaPalavra e-Periódico, Florianópolis, v. 12, n. 11, p. 36-59, jul./dez. 2013.

PITT, H. The waste is out of fashion. 2012. Disponível em: <http://timorissanen.files.wordpress.com/2012/06/ sydneymorningherald9-10-2011.pdf>. Acesso em: 23 mar. 2013

RIBEIRO, A.; BARCELOS, S. M. B.; DAMASCENO. Modelagem Zero Waste Aplicada ao Conceito Slow. In: COLÓQUIO DE MODA, 9, 2012, Rio de Janeiro. Disponível em: <http://www.coloquiomoda.com.br/ anais/8-coloquio-de-moda-gt10_comunicacao-oral.php>. Acesso em: 30 out. 2013.

RISSANEN, T.; MCQUILLAN, H. YIELD: making fashion without making waste. 2011. Disponível em: <http://www.yieldexhibition.com/ yieldexhibition-catalogue.pdf>. Acesso em: 23 mar. 2013.

ROBERTS, J. Julian and subtraction cutting - part 1. Entrevista concedida a Zoe Romano. Disponível em: <http://openwear.org/blog/?p=1249>. Acesso em: 24 abr. 2013.

ROSENBLOOM, S. Fashion tries on zero waste design. 2010. Disponível em: <http://www.nytimes.com/2010/08/15/fashion/15waste.html?_ $r=5 \&$ ref=style\& $>$. Acesso em: 2 maio 2013.

SEIFFERT, M. E. B. ISO 14001 Sistemas de Gestão Ambiental: implementação objetiva e econômica. 4. ed. São Paulo: Atlas, 2011. 
VEZZOLI, C. Design de sistemas para a sustentabilidade: teoria, métodos e ferramentas para o design sustentável de "sistemas de satisfação". Salvador: EDUFBA, 2010.

Recebido em:27/01/14

Aprovado em:01/07/14 